\section{A democratização do planejamento da política pública de educação municipal na região do Alto Tietê-SP}

\section{The democratization of the education public policies's planning in the municipalities in the region of Alto Tietê-SP}

\author{
Fabiana Barbosa Brígido ${ }^{1}$ \\ Ricardo Luiz Pereira Bueno ${ }^{2}$ \\ Marcello Simão Branco ${ }^{3}$
}

\begin{abstract}
Resumo
O processo de planejamento das políticas públicas municipais envolve a participação de diversos atores. $\mathrm{O}$ avanço nas pesquisas na área de políticas públicas contribuiu para o surgimento de estruturas de organização que permitiram uma melhor gestão do financiamento e um maior incentivo à participação popular na elaboração dessas políticas. Este artigo aborda, em termos práticos, como a construção dos Planos Municipais de Educação da região conhecida como Alto Tietê, no Estado de São Paulo, reflete as dificuldades dos municípios em desenvolver política pública, por meio de uma gestão compartilhada, que garanta participação social e a publicidade de ações. Esta pesquisa revela que a construção de políticas públicas que tragam respostas à sociedade depende de uma maior transparência na gestão pública, o que se faz por intermédio da disponibilização de uma ampla gama de informações e serviços por meio de canais de comunicação das prefeituras, sendo a internet a principal delas.
\end{abstract}

Palavras-chave: Educação; Planejamento; Políticas Públicas; Transparência.

\begin{abstract}
The planning process of municipal public policies involves the participation of many actors. Advances in research in the area of public policy contributed to the emergence of organizational structures that allow better management of funding and more encouraging public participation in the preparation of policies. This article discusses, in practical terms, as the construction of Municipal Education Plans in the area known as Alto Tietê in São Paulo, reflecting the difficulties of the municipalities in developing public policy through shared management that ensures social participation and advertising actions. This research shows that the construction of public policies that bring answers to society depends on greater transparency in public management, which is done by providing a wide range of information and services through the communication channels of local governments, the Internet being the main one.
\end{abstract}

Key-words: Education; Planning; Public Policies; Accountability.

\footnotetext{
${ }^{1}$ Fabiana Barbosa Brígido Mestranda em Gestão de Políticas e Organizações Públicas - Universidade Federal de São Paulo - UNIFESP. E-mail: fabianabrigido@yahoo.com.br

${ }^{2}$ Ricardo Luiz Pereira Bueno Doutor em Administração pela Universidade Federal do Rio Grande do Sul (UFRGS). Email: ricardolpbueno@gmail.com

${ }^{3}$ Doutor em Ciência Política pela Universidade de São Paulo (USP). E-mail: marcellobranco@ig.com.br
}

Artigo recebido em: 15 de agosto de 2016. Artigo aceito em 01 de fevereiro de 2017. 


\section{INTRODUÇÃO}

As últimas décadas registraram um debate acerca da função do Estado na sociedade, mais especificamente a respeito do papel das políticas públicas para o desenvolvimento do país, propiciando uma maior visibilidade do campo de conhecimento que trata a respeito das políticas públicas, tanto as econômicas quanto as sociais (SOUZA, 2006, p. 20).

Nesse período, houve um incremento das pesquisas sobre políticas públicas e um avanço da legislação, que implicou na criação de estruturas de organização que permitiram uma melhor gestão do financiamento e um maior incentivo à participação popular na elaboração das políticas públicas. Observa-se porém que, na prática, a participação popular ainda é tímida, isso porque os mecanismos de controle e de transparência ainda não foram democratizados efetivamente (POSSAMAI, 2011).

Em federações, como a do Brasil, territórios são regulados por diversas esferas de governo, cada um com competências exclusivas e/ou compartilhadas, o que exige uma combinação entre autonomia e interdependência dos níveis de governo para a formulação e implementação das políticas públicas. A Constituição Federal de 1988 garantiu a autonomia dos governos locais e ressaltou a importância da União na coordenação federal a fim de corrigir as desigualdades territoriais e na suplementação ou indução de ações no plano subnacional (SEGATTO; ABRUCIO, 2016).

Nessa perspectiva, os municípios passaram a ter competências legislativas concorrentes à União e aos Estados em algumas áreas, entre elas, a educação, e isso permitiu que se tornassem também formuladores de políticas públicas, compreendidas por um fluxo de decisões públicas que têm por objetivo manter o equilíbrio social ou de introduzir desequilíbrios a fim de modificar uma realidade (SARAIVA, 2006).

A política pública é formada por um conjunto de intenções estratégicas, associadas a instrumentos, que permitem sua execução a partir da ação de agentes governamentais, da sociedade civil organizada ou de agentes de mercado (PROCOPIUCK, 2013, p. 141). Ou dito de outra forma, política pública é observar $o$ Estado em ação e, por consequência, a opção política que justifica determinada decisão e gestão em alguma área. Seja em educação, saúde, transporte etc.

Este trabalho busca analisar a democratização do planejamento da política pública de educação, por meio da disponibilização das informações referentes aos 
Planos Municipais de Educação (PME) da região conhecida como Alto Tietê, no Estado de São Paulo. Partimos do pressuposto de que o PME é um instrumento de planejamento estratégico de longo prazo, que norteará a alocação de recursos e a implementação de políticas públicas na área de educação no município para os próximos dez anos (BRASIL, 2014). Observa-se, ainda, se foi garantida a participação popular na construção dos planos, por meio da realização de audiências públicas, e se os planos encontram-se disponíveis eletronicamente para o acesso da população.

As informações foram pesquisadas nos sítios eletrônicos das prefeituras que compõem a Região do Alto Tietê (Arujá, Biritiba Mirim, Ferraz de Vasconcelos, Guararema, Guarulhos, Itaquaquecetuba, Mogi das Cruzes, Poá, Salesópolis, Santa Isabel e Suzano), pois é notória a necessidade de haver a democratização digital das informações por parte dos governantes, a fim de permitir que a população acompanhe e fiscalize a execução dos planos de educação. Por democracia digital compreende-se a utilização de ferramentas de participação eletrônica no ciclo de políticas públicas, com o objetivo de promover a disseminação de informações e o controle social da gestão pública (POSSAMAI, 2011).

Assim, a pesquisa espera verificar se os municípios da Região do Alto Tietê compreendem os Planos Municipais de Educação como ferramentas de gestão estratégica e democrática das políticas públicas de educação locais.

\section{REFERENCIAL TEÓRICO}

1.1 As políticas públicas a partir da Constituição de 1988

Na década de 1980, existia um pessimismo quanto à capacidade do governo resolver problemas econômicos e sociais, reflexo da combinação que herdamos da ditadura militar: uma mistura de "autoritarismo com clientelismo, hipertrofia com opacidade, insulamento com intervencionismo, deficitarismo com megalomania" (DAGNINO; COSTA, 2013, p. 16), o que gerou na população uma ausência de perspectivas de melhora desse quadro.

Durante a ditadura militar, o governo federal gerenciava uma proporção exagerada dos recursos e centralizava diversas decisões quanto às políticas públicas no Brasil (FARAH, 2001, p. 122 e 123). O papel das unidades federativas era apenas 
secundário, com uma atuação mais voltada para a execução das políticas públicas, de acordo com o determinado pelo governo federal, consequência direta de muitos anos de governo autoritário no comando da política nacional (ALMEIDA, 2007).

Esse quadro muda com a introdução do novo governo civil e a promulgação da Constituição Federal de 1988, que cria a figura do município como ente federativo com autonomia, fragmentando e descentralizando o planejamento e a implementação das novas políticas públicas (ARRETCHE, 2000, p. 47).

A partir desse marco legal, vislumbra-se uma atmosfera de maior credibilidade, passando, o Estado, a ser percebido como detentor de uma maior competência no que se refere à sua capacidade de intervenção na realidade social. Esse fato foi propiciado pela alteração na dinâmica de relacionamento entre o Estado e a sociedade, pois a retomada plena das relações federativas no Brasil, com a Constituição de 1988, permitiu uma distribuição das competências entre os três níveis de governo. Além disso, contribuiu para que as políticas sociais passassem a ser pensadas por pessoas que estão mais próximas aos problemas considerados públicos, as chamadas administrações locais, novos atores na consecução de políticas (ALMEIDA, 2007).

Para Secchi (2014, p. 124) políticas públicas (public policies) "são diretrizes elaboradas para enfrentar um problema público”. Souza (2006, p. 26), ainda, define política pública como o campo do conhecimento que busca "colocar o governo em ação" e analisar essa ação a fim de propor mudanças em seu curso. Procopiuck (2013, p. 141) delimita política pública em um conjunto de diretrizes que desenham a ação governamental, "suas bases se encontram na legislação, em ordens executivas, em sistemas de controles institucionais, dentre outros".

$1.2 \mathrm{O}$ processo de formulação das políticas públicas: O Ciclo das Políticas Públicas

O processo de elaboração de políticas públicas (policy-making process), segundo Secchi (2014), é conhecido como ciclo de políticas públicas (policy cycle) e pode ser representado por sete fases principais: identificação do problema, formação da agenda, formulação das alternativas, tomada de decisão, implementação, avaliação e extinção.

Problema público pode ser definido como a diferença entre uma situação considerada ideal comparativamente a uma situação real. É aquilo que está aquém do mínimo necessário e entendido como suficiente. É nessa fase que é identificada uma 
situação indesejada que pode ser resolvida por meio da intervenção pública. Easton (1968, p. 164) utiliza o termo demanda para caracterizar expressões articuladas dirigidas às autoridades, propondo que algum tipo de alocação de autoridade precisa ser realizado.

A agenda determina os objetos e os agentes de conflito no Poder Público (FERNANDES, 2007, p. 205), isto é, problemas ou temas entendidos como relevantes. Segundo os autores, Cobb e Elder (1983), existem duas agendas: a agenda política e a agenda formal. A agenda política é o conjunto de temas e/ou problemas que são percebidos pela comunidade política como merecedores de uma intervenção pública. Já a agenda formal ou agenda institucional é aquela que relaciona temas e/ou problemas que, de fato, serão objeto de ação do poder público.

A etapa da formulação de propostas ou alternativas compreende a formulação da política em si, pois é nesse momento que são estudadas as possíveis soluções ao problema público e são elaboradas as ações (métodos, programas, estratégias) para alcançar os objetivos estabelecidos. Quanto mais concretos forem os objetivos (mensuração em metas), tanto mais fácil será verificar a eficácia de uma política (SILVA, p. 74, 2012).

A tomada de decisão é realizada pelos atores que têm capacidade e autoridade para tomar decisões públicas vinculativas. Assim, participam dessa etapa os políticos, os juízes e os funcionários de governo investidos de autoridade para tomar decisões oficiais (HOWLETT; RAMESH; PERL, 2013, p. 158). Os demais atores que participam do processo de elaboração das políticas públicas têm seus questionamentos respondidos com a explicitação do enfrentamento ao problema. É importante salientar que essas decisões podem tanto perpetuar o status quo quanto promover a alteração dele (CORAIOLA, 2015).

Uma importante fase é a implementação, momento em que são produzidos os resultados concretos da política pública, isto é, as intenções são convertidas em ações. Existem dois modelos teóricos de implementação de políticas públicas, a saber: de cima para baixo - top-down e de baixo para cima - bottom-up (LIMA; D'ASCENZI, 2013). No modelo top-down, as políticas públicas são elaboradas e decididas pelos agentes políticos, sendo um mero esforço administrativo a sua implementação. Já no modelo bottom-up, os implementadores têm maior participação na seleção do problema e na prospecção de soluções durante a implementação e, posteriormente, os tomadores de 
decisão ratificam as práticas efetuadas (SECCHI, 2014).

A avaliação é a etapa do ciclo das políticas públicas (policy cycle) em que se apreciam os programas já implementados quanto ao alcance dos resultados pretendidos (eficácia), comparativo entre o esforço empregado e os resultados alcançados (eficiência) e o impacto sobre o problema considerado (efetividade) (MARQUES, 2013; FINKLER; DELL'ÁGLIO, 2013). Analisam-se as deficiências e os efeitos colaterais indesejados para se delimitarem as ações e programas futuros. Nessa etapa, caso os objetivos do programa tenham sido atingidos, o ciclo político pode ser suspenso ou extinto, em caso contrário, há iniciação de um novo ciclo, isto é, de uma nova fase de percepção e definição de problemas (TREVISAN; BELLEN, 2008, p. 531).

Após passar pelas fases do ciclo, uma política pública pode chegar ao fim. Secchi (2014, p. 67) define as três causas da extinção de uma política pública: o problema que originou a política é percebido como resolvido, os programas, as leis ou as ações que ativavam a política pública são percebidos como ineficazes, ou ainda, o problema, embora não resolvido, perdeu progressivamente importância e saiu das agendas políticas e formais.

\subsection{Análise das políticas públicas}

A análise de política pública permite compreender o que os governos fazem, por que fazem e que diferença isso faz (DYE, 1976). Como já dito, políticas públicas, portanto, envolvem atividade política. Nessa perspectiva, faz-se importante conhecer como se dá a participação dos atores políticos no processo de tomada de decisão.

Para explicar o processo de elaboração de políticas, Easton (1968, p. 154) considera o impacto dos acontecimentos do meio ambiente no sistema político. Para o autor, um sistema político é apenas uma maneira de converter certos tipos de inputs em outputs, onde inputs são demandas (reinvindicações por serviços públicos como educação, saúde, segurança) e apoio ou suporte (atos de participação política, como o voto, direcionamento de forças para determinado grupo que pode estar vinculado diretamente a uma política); enquanto outputs se referem às decisões e ações das autoridades, respostas que podem, inclusive, gerar novas demandas (EASTON, 1970, p. 195 e 196).

Verifica-se que a tomada de decisão é realizada por um grupo de atores que têm 
competência e responsabilidade para tal. Isso é importante para compreender uma das teorias explicativas da tomada de decisão: a abordagem estatista (state-centred policymaking), que tem por pressuposto considerar que as políticas públicas são, analiticamente, monopólio dos atores estatais em razão de sua personalidade jurídica e de sua superioridade objetiva em fazer leis (SALISBURY, 1995, p. 34). Os agentes políticos, detentores de parcela do poder outorgado pelo povo, e que, em nome dele, criam e executam as leis, são, segundo a abordagem estatista, os principais atores responsáveis pela condução das políticas públicas.

Partindo da abordagem estatista, é possível dizer que o Estado implementa políticas públicas por meio do processo legislativo, criando as leis, mas também se submetendo a elas: "a formulação de políticas públicas constitui-se no estágio em que os governos democráticos traduzem seus propósitos e plataformas eleitorais em programas e ações que produzirão resultados ou mudanças no mundo real" (SOUZA, 2006, p. 26).

Há ainda outros dois modelos explicativos da tomada de decisão em políticas públicas: a teoria centrada na sociedade (society centered), que parte do pressuposto de que a tomada de decisão sofre pouca ou nenhuma influência dos atores públicos. Segundo Deubel (2002, p. 30), os estudiosos dessa corrente "minimizam a capacidade e o impacto que as instituições públicas, seus agentes e seus valores podem realizar sobre as escolhas feitas em matéria de políticas públicas". Por fim, Matias-Pereira (2012, p. 65), citando Deubel (2006), explica que o último modelo, a teoria mista, busca um equilíbrio entre os determinantes internos (state centered) e externos (society centered).

Pode-se também analisar a política pública como um processo incremental, linha teórica que esclarece que as "decisões tomadas no passado constrangem decisões futuras e limitam a capacidade dos governos de adotar novas políticas públicas ou de reverter a rota das políticas atuais”. O incrementalismo foi desenvolvido por Charles Lindblom, que identificou que recursos governamentais para programas, órgãos ou políticas públicas não partem do zero, mas de decisões incrementais (SOUZA, 2006, p. 29).

O modelo incremental identifica a tomada de decisão como uma atividade menos técnica e mais política, se comparada com o modelo racional. Enquanto o modelo racional de tomada de decisão é o preferível por mostrar como deveriam ser tomadas as decisões para assegurar resultados "máximos", o modelo incremental 
descreve melhor a prática "real" da tomada de decisão nos governos (HOWLETT; RAMESH; PERL, 2013, p. 161).

Observa-se, ainda, que a elaboração das políticas públicas ocorre em meio a uma disputa de poder. Nessa perspectiva, os interesses organizados competem, perseguindo suas preferências, cabendo ao Estado garantir a legitimidade da competição e a observância das regras colocadas (ARAÚJO; TAPIA, 1991, p. 4).

O pluralismo é um modelo teórico utilizado para analisar o sistema político, principalmente o que tange a análise da tomada de decisões e as relações entre interesses sociais e o poder público. Assim, o pluralismo prevê a "existência de um sistema em que as decisões provêm da interação e da competição de uma multiplicidade de grupos representando interesses sociais diversos, cabendo ao Estado à função de mero árbitro na solução dos interesses conflitantes” (MAGANO, 1983, p. 57). Porém, acredita-se que o pluralismo é inadequado quando se deseja explicar a dinâmica política e as transformações ocorridas nas formas institucionais entre Estado e interesses de classe organizados (ARAÚJO; TAPIA, 1991).

Assim, em contraponto ao pluralismo, desenvolveu-se o estudo do modelo de Estado corporativista. Para os autores corporativistas, as formas de representação são estruturadas de modo a permitir uma competição limitada de um pequeno número de organizações, fortemente centralizadas, que detém o monopólio da representação, e não pelo livre jogo de grupos em disputa por recursos de poder dispersos na sociedade (ALMEIDA, 2003). Com esse enfoque, as políticas públicas não são concebidas como o resultado da competição entre grupos, como trata a teoria pluralista, mas como o fruto de uma negociação entre o Estado e os representantes dos grupos interessados (DEUBEL, 2002, p. 32).

Porém, ao longo dos últimos cinquenta anos, alguns deslocamentos na literatura sobre políticas públicas reduziram a importância da racionalidade e do processo de decisão na formulação das políticas e trouxeram ao centro outros momentos do ciclo da produção de políticas, como a formação da agenda e sua implementação. A mudança de enfoque destacou o papel das agências estatais, burocratas e instituições (MARQUES, 2013, p. 24).

Segundo Procopiuck (2013, p. 101), as instituições são constituídas por conjuntos complexos de práticas e significados, que influenciam ações individuais e coletivas em diversos contextos. Assim, de forma sintética, as instituições podem se 
apresentar como simples regras e fundamentar um comportamento político. As regras podem ser formais, como aquelas advindas da legislação ou ainda informais, como padrões culturais que influenciam comportamentos. Segundo o autor, considerando-se, conjuntamente, a existência de estruturas e normas, é possível inferir que não há políticas organizadas sem instituições.

\subsection{As Políticas Públicas como Sistemas e a Teoria Institucional}

Para facilitar a gestão de forma articulada entre os entes federativos, algumas políticas públicas estão organizadas em sistemas: é o caso do Sistema Nacional de Cultura (SNC), o Sistema Único da Assistência Social (SUAS), o Sistema Nacional de Habitação (SNH), e o mais bem-sucedido deles: o Sistema Único de Saúde (SUS) (BORGES; TOMETICH, 2014).

A política de educação não segue a estrutura de um sistema. O planejamento de longo prazo ocorre por intermédio dos Planos de Educação, de vigência decenal. Saviani (2010) aponta os obstáculos que, ao longo da História, impediram a organização do Sistema Nacional de Educação no Brasil, classificando-os em quatro tipos:

a) os obstáculos econômicos decorrentes da histórica resistência à manutenção da educação pública no Brasil; b) os obstáculos políticos caracterizados pela descontinuidade nas políticas educativas; c) os obstáculos filosófico-ideológicos, isto é, a prevalência das ideias ou mentalidades pedagógicas refratárias à organização da educação na forma de um sistema nacional; d) os obstáculos legais materializados na resistência à incorporação da ideia de sistema nacional na nossa legislação educacional, cuja ponta de lança se ancorava na suposta e logicamente inconsistente tese da inconstitucionalidade da proposta de Sistema Nacional de Educação (SAVIANI, 2010, p. 381).

A criação de sistemas permite que a elaboração e a execução das políticas públicas se deem de forma estruturada, coordenada, integrada, com funções específicas (MORGAN, 1996, p. 49 e 50) para cada ente federado, respeitando-se as competências constitucionais de cada um.

Esse processo de homogeneização da forma de gestão das políticas pode ser definido por DiMaggio e Powel (2006, p. 120) como isomorfismo. A teoria institucional define que, a fim de superar as incertezas presentes no campo organizacional, instituições tendem a se tornar semelhantes. Isso se dá pelo fato de ações bem-sucedidas serem imitadas por outras instituições, buscando-se o êxito em sua execução. Rossetto e Rossetto (2005) definem:

O isomorfismo é um conjunto de restrições que forçam uma unidade

Revista Eletrônica Gestão e Serviços v.7, n. 2, pp. 1727-1750, Julho/Dezembro 2016.

ISSN Online: 2177-7284 e-mail: regs@metodista.br 
de uma população a parecer-se com outras unidades que se colocam em um mesmo conjunto de condições ambientais. Tal abordagem sugere que as características organizacionais são modificadas na direção do aumento de compatibilidade com as características ambientais; o número de organizações em uma população é função da capacidade ambiental projetada e a diversidade das formas organizacionais é isomórfica à diversidade ambiental.

Há dois tipos de isomorfismo: o competitivo e o institucional. O isomorfismo competitivo relaciona-se com ações de competição de mercado, nos campos onde a competição é livre e aberta, como a mudança de nicho e medidas de ajustamento. A visão institucional do isomorfismo salienta que, uma vez que "as organizações não competem apenas pelos recursos e consumidores, mas pelo poder político e legitimação institucional, por ajustamento social, bem como econômico", esse conceito se configura como um instrumento importante para conceber a política e os rituais que tangenciam a vida organizacional moderna (DIMAGGIO; POWEL, 2006, p. 121).

Em seu estudo, os autores DiMaggio e Powel (1983, p. 150) identificam três mecanismos por meio dos quais ocorre a mudança isomórfica institucional: 1) $\mathrm{O}$ isomorfismo coercitivo deriva de pressões formais e informais exercidas por outras organizações das quais dependem, assim, como exemplo, pode-se citar a regulamentação governamental de determinado campo de exploração que exigirá mudanças na organização; 2) $\mathrm{O}$ isomorfismo mimético deriva das respostas padronizadas sob condições de incerteza, fazendo que as organizações se espelhem umas nas outras, o que proporciona uma solução viável e de baixo custo em situações com causas ambíguas e de saídas pouco claras; e, 3) O isomorfismo normativo está associado à profissionalização, por exemplo, quando atores externos podem induzir uma organização a realizar determinadas atividades especificando a profissão responsável pelo seu desenvolvimento.

No Brasil, o Sistema Único de Saúde (SUS) foi um precursor dos demais sistemas de políticas, por ter obtido êxito em sua implementação, sendo considerado a maior política de inclusão social da história do Brasil (MENDES, 2013).

Esse sucesso levou o Estado a utilizá-lo como modelo, aplicando o isomorfismo coercitivo na construção dos demais sistemas, a partir da aprovação de leis que garantiriam direitos à população, instituindo obrigações para a União, Estados e Municípios, em uma perspectiva que garantiu uma maior cooperação entre os entes federados (ABRUCIO, 2013, p. 211). 
2.5 A Educação como Política no Estado Federativo pós-1988

O federalismo pode ser entendido como um sistema político com divisão de poder dentro de um território, no qual os governos subnacionais - Estados, províncias, cantões ou, até mesmo, municípios, como no Brasil - realizam um pacto (BRANCO, 2007). A federação tornou-se, por excelência, a forma de organização do Estado Democrático, visto que a descentralização do poder é um instrumento de exercício da democracia (GARCIA, 2013, p. 181).

Toda federação deriva de condições que conformam um cenário específico de heterogeneidades, que dividem e criam conflitos em determinada nação. Podem existir disparidades em decorrência de demasiada extensão territorial ou diversidade física, conformação étnica, fatores linguísticos, desigualdades socioeconômicas regionais, culturais e políticas, as últimas ocasionadas por diferenças no processo de formação das elites e/ou a presença de uma forte rivalidade entre elas. Assim, as federações existem para dar conta de uma ou mais heterogeneidades (ABRUCIO, 2013, p. 206).

Entre as federações existentes, o Brasil é o único que conferiu aos municípios a condição de ente federativo com autonomia e capacidade para executar atividades administrativas, legislativas e políticas de forma descentralizada (PRADO, p. 140, 2013).

Como os entes passaram a dispor de autonomia para a execução das políticas públicas, a fim de que houvesse um compromisso de todos com a oferta e o desenvolvimento da educação, além da superação das disparidades regionais, a Constituição Federal de 1988 definiu um investimento mínimo para cada um dos entes federativos e a criação de fundos de manutenção da educação (BRASIL, 2003).

A Constituição Federal de 1988 determina que os municípios apliquem ao menos $25 \%$ de sua receita de impostos e transferências entre governos na manutenção e desenvolvimento da educação. Os Estados devem aplicar o mesmo percentual e a União, no mínimo $18 \%$.

A criação dos fundos foi realizada por meio de uma Emenda à Constituição e possibilitou uma melhor coordenação federativa das políticas de educação (ABRUCIO, 2013). Cada Estado deveria possuir o seu fundo, composto, basicamente, por recursos dos próprios Estados e municípios, originários de fontes já existentes (Fundo de Participação dos Estados - FPE, Fundo de Participação dos Municípios - FPM, Imposto sobre Circulação de Mercadorias e Serviços - ICMS e Imposto sobre Produtos 
Industrializados, proporcional às exportações - IPI exp.), acrescidos de uma parcela de recursos novos, originários da União, que seria um suplemento à quantia necessária para equalizar o investimento per capita em municípios cujos gastos não atingissem o gasto mínimo nacional per capita, definido na lei orçamentária anual do país (MELO 2005, p. 874).

Assim, o Fundo de Manutenção e Desenvolvimento do Ensino Fundamental e de Valorização do Magistério - Fundef - foi instituído no governo Fernando Henrique e baseava-se na distribuição dos recursos de acordo com o número de matrículas nos estabelecimentos de ensino dos entes federados. Dessa forma, as prefeituras empenharam-se em atrair novos alunos, pois receberiam uma maior transferência, o que resultou na quase universalização do acesso à escola da população de 7 a 14 anos de idade (97\%) (GOMES, 2013, p. 270). A criação do Fundef incentivou a descentralização dos Estados para os municípios, pois poderia haver transferência negativa caso o Estado continuasse a executar a política de educação (MELO, 2005, p. 874).

Já no governo Lula, o Fundo de Manutenção e Desenvolvimento da Educação Básica e de Valorização dos Profissionais da Educação - Fundeb - substituiu o Fundef. O novo fundo trouxe alterações, incluindo novas fontes de financiamento, ampliando a incidência de 15\% para 20\% sobre essas fontes, acrescentou matrículas a serem atendidas, ampliando o escopo do FUNDEF e manteve a complementação mínima a ser realizada pela União (DAVIES, 2006; GOMES, 2013).

Assim, os fundos significaram mecanismos de vinculação do financiamento da educação, compostos por transferências obrigatórias, e que garantiriam um mínimo constitucional de aplicação nessa política pública. Ainda que não tenham instituído um padrão de qualidade, a existência de tal estrutura de financiamento propiciou avanços e destacou a importância do controle sobre a aplicação dos recursos a ser exercido pelos órgãos de fiscalização e pela sociedade civil (DAVIES, 2006, p. 771).

2.6 A democratização da gestão das políticas públicas

A população tem cobrado uma postura ética e transparente na gestão da máquina pública. Nesse novo ambiente democrático de controle social, surgiram iniciativas legislativas para controlar os gastos públicos. Em 2000, foi promulgada a Lei de 
Responsabilidade Fiscal (LRF) que instituiu regras de finanças públicas para a responsabilização da gestão fiscal, e obrigou uma ampla divulgação dos orçamentos públicos, inclusive em meios eletrônicos (CAMPOS; PAIVA; GOMES, 2013).

As diretrizes de governo eletrônico foram propostas, em 2003, pelo Ministério do Planejamento, Orçamento e Gestão. O documento define que a gestão do conhecimento deve "assegurar a habilidade de criar, coletar, organizar, transferir e compartilhar conhecimentos estratégicos que podem servir para a tomada de decisões, para a gestão de políticas públicas e para inclusão do cidadão como produtor de conhecimento coletivo" (BRASIL, 2016). Segundo Rothberg (2010), ainda que teoricamente, se reconhece nesse documento uma mudança de paradigma, visto que não basta prestar serviços pela rede; ela deve ser usada para a construção compartilhada de políticas públicas.

Foi somente em 2010, com a entrada em vigor da Lei Complementar 131/2009, a Lei de Acesso à Informação (LAI), que houve a obrigatoriedade da disponibilização em tempo real de informações pormenorizadas sobre a execução financeira e orçamentária da União, Estados, Distrito Federal e Municípios (CAMPOS; PAIVA, 2013).

O Brasil segue uma iniciativa internacional, a Open Goverment Partnership (OGP) ou Parceria para Governo Aberto, lançada em 2011, que pretende difundir e incentivar práticas governamentais em todo o mundo, de forma a dar mais transparência aos governos, incentivar a participação popular e o acesso à informação. O documento norteador da OGP é a Declaração de Governo Aberto, uma carta fundamentada na Declaração Universal dos Direitos Humanos, na Convenção das Nações Unidas contra a Corrupção e em outros instrumentos internacionais aplicáveis relacionados aos direitos humanos e à boa governança. Os 65 países signatários, entre eles o Brasil, comprometem-se, entre outros aspectos, a aumentar a disponibilidade de informações sobre as atividades governamentais e a ampliar o acesso a novas tecnologias para fins de abertura e prestação de contas (BRASIL, 2016).

Nesse sentido, soluções de Governo Aberto, principalmente aquelas fundamentadas em tecnologia da informação, têm sido adotadas pelos governos a fim de aproximar e facilitar a relação do Estado com o cidadão, oferecendo serviços, acelerando processos e aumentando a transparência e a participação social (BERBERIAN; MELLO; CAMARGO, 2014). 


\section{MÉTODO}

Para esta pesquisa foram colhidas as informações disponibilizadas pelos municípios em relação à política pública de educação. Em dezembro de 2015, foram consultados todos os endereços eletrônicos das prefeituras que compõem a região do Alto Tietê, no Estado de São Paulo, totalizando 11 municípios. A pesquisa nos sites buscou coletar as seguintes informações:

1. O cumprimento dos prazos de apresentação dos Planos Municipais de Educação (PME). A partir da aprovação do Plano Nacional de Educação em junho de 2014, os Estados e municípios teriam o prazo de um ano para aprovar os planos locais. O PME é uma importante peça de planejamento, norteador da política de educação. Com vigência de dez anos, o documento estipula as metas a serem alcançadas pelo município através da promoção de ações, programas e políticas públicas, cujo financiamento deve estar previsto no orçamento municipal. Esse aspecto foi escolhido para análise, pois o atraso na elaboração dos planos poderia comprometer o planejamento orçamentário e a execução da política pública.

2. A participação popular na elaboração dos Planos Municipais de Educação, por meio do chamamento de Audiências Públicas para tratar sobre o tema; e,

3. A publicização do planejamento de ações para o desenvolvimento da política de educação local. Para isso, foi pesquisado se a gestão divulgou o plano de governo em endereço eletrônico na Internet e se este mencionava as ações na área de educação.

Quando não havia informações sobre a aprovação dos planos nos endereços eletrônicos dos municípios, realizou-se a busca de informações no site do Ministério da Educação (PNE) em Movimento (BRASIL, 2015) que disponibiliza o acompanhamento à situação dos planos de educação em todo território nacional.

\section{RESULTADO}

A partir das informações obtidas, foi elaborada uma tabela para uma melhor análise, contendo os municípios da Região do Alto Tietê, a data da aprovação dos 
respectivos planos de educação, se ocorreram audiências públicas para a discussão dos planos e se este está disponível no site da prefeitura para consulta e, por fim, se houve a divulgação de um plano de governo contendo metas para a educação no município.

Tabela 1 - Municípios e a publicidade de suas ações

\begin{tabular}{|c|c|c|c|c|}
\hline Municípios & $\begin{array}{c}\text { Data da } \\
\text { Aprovação do } \\
\text { Plano de } \\
\text { Educação }\end{array}$ & $\begin{array}{c}\text { Há informações } \\
\text { sobre a } \\
\text { realização de } \\
\text { Audiências } \\
\text { Públicas? }\end{array}$ & $\begin{array}{c}\text { O Plano } \\
\text { Municipal de } \\
\text { Educação está } \\
\text { disponível no } \\
\text { site? }\end{array}$ & $\begin{array}{l}\text { Há plano de } \\
\text { governo com } \\
\text { metas para a } \\
\text { educação? }\end{array}$ \\
\hline Arujá & $24 / 06 / 2015$ & Não & Sim & Não \\
\hline Biritiba Mirim & $3 / 06 / 2015$ & Sim & Não & Não \\
\hline $\begin{array}{c}\text { Ferraz de } \\
\text { Vasconcelos }\end{array}$ & $23 / 06 / 2015$ & Sim & Não & Não \\
\hline Guararema & $17 / 06 / 2015$ & Não & Sim & Não \\
\hline Guarulhos & - & Não & Não & Sim \\
\hline Itaquaquecetuba & $24 / 06 / 2015$ & Não & Sim & Não \\
\hline Mogi das Cruzes & $27 / 03 / 2015$ & Não & Não & Não \\
\hline Poá & $23 / 06 / 2015$ & Não & Não & Não \\
\hline Salesópolis & $13 / 10 / 2015$ & Sim & Sim & Não \\
\hline Santa Isabel & $20 / 10 / 2015$ & Não & Não & Não \\
\hline Suzano & $23 / 06 / 2015$ & Sim & Não & Não \\
\hline
\end{tabular}

Em dezembro de 2015, Guarulhos havia realizado consulta pública, mas não enviou seu plano ao legislativo; os demais dez municípios já tinham aprovado seus planos.

Arujá: a lei que instituiu o Plano Municipal de Educação foi sancionada em junho de 2015. O texto se encontra no site da Prefeitura, é possível encontrá-lo fazendose a busca por "legislação", palavras-chave "Plano Municipal de Educação". Não há informações sobre a realização de audiências públicas para discussão e apresentação do Plano à população. A prefeitura não oferece dados a respeito do seu plano de ação, ou 
de iniciativas na área da educação que serão realizadas na gestão atual.

Biritiba Mirim: aprovou o Plano dentro do prazo estipulado pelo governo federal. No site da prefeitura há uma publicação sobre a realização de uma audiência pública no dia 27 de maio de 2015 que discutiu o Plano de Educação, porém o Plano aprovado não está disponível no site. Não há informação a respeito do plano de governo ou acerca da política de educação.

Ferraz de Vasconcelos: realizou uma audiência pública no dia 12 de maio de 2015, segundo informações obtidas no site da prefeitura. O plano de governo e o planejamento da área de Educação não estão no site, e o Plano de Educação também não está disponível. Apesar de haver uma página com a legislação municipal, o conteúdo está atualizado apenas até 2014.

Guararema: sancionou a Lei que cria o Plano Municipal de Educação em 17 de junho de 2015, o documento está disponível no site da prefeitura dentro da pesquisa por "legislação municipal”, porém não há um documento que trate sobre o planejamento da educação municipal no site, nem ao menos o plano de governo da administração.

Guarulhos: O Projeto de Lei não foi enviado ao Legislativo, assim, não foram realizadas audiências públicas para a discussão do Plano. A prefeitura disponibiliza dentro do site da Secretaria de Educação o Plano de Ação na área de educação, para os anos de 2013 a 2016, os quatro anos da gestão atual.

Itaquaquecetuba: a lei foi sancionada em 24 de junho de 2015 e está disponível com a legislação do município, porém não há quaisquer informações sobre a realização de audiência pública para discutir o tema. Não consta plano de ação na área de educação ou plano de governo.

Mogi das Cruzes: na página da Secretaria de Educação constam três planos de educação, de vigência bienal, iniciando em 2009 e concluindo em 2014. Não consta o último plano, para os próximos dez anos, nem o plano de governo do município com as ações na área da educação.

Poá: não há informações sobre audiências públicas para a aprovação do Plano Municipal de Educação, somente a informação acerca de um fórum que daria início aos trabalhos de elaboração do plano. Não foi encontrada menção sobre o planejamento de governo, nem ao menos a respeito das ações na área da educação. O Plano Municipal de Educação não está disponível no site da prefeitura.

Salesópolis: a lei que institui o Plano de Educação foi promulgada em 13 de 
outubro de 2015. A prefeitura divulgou a consulta pública para a elaboração do plano no dia 3 de junho de 2015 e a audiência pública para apresentação do Plano no dia 23 de novembro de 2015. O Plano Municipal de Educação encontra-se publicado com as demais leis municipais.

Santa Isabel: A lei que institui o Plano de Educação foi promulgada em 20 de outubro de 2015, cujo texto está disponível entre as leis municipais. Não há informações sobre planejamento municipal de educação e plano de governo.

Suzano: O Plano Municipal de Educação foi publicado no dia 23 de junho de 2015. No site da prefeitura há informações sobre uma conferência que tinha por objetivo discutir o texto base do Projeto de Lei que instituiria o Plano Municipal de Educação. Não há plano de governo disponível ou informações acerca de ações na área de educação.

\section{ANÁLISE DOS DADOS E DISCUSSÃO DE RESULTADOS}

Das 11 cidades que compõem a Região do Alto Tietê: Arujá, Biritiba Mirim, Ferraz de Vasconcelos, Guararema, Itaquaquecetuba, Guarulhos, Mogi das Cruzes, Poá, Salesópolis, Santa Isabel e Suzano, apenas 33\% não cumpriram o prazo para a apresentação do Plano Municipal de Educação, estipulado no texto do Plano Nacional (BRASIL, 2014) e que findaria em julho de 2015.

A partir das informações colhidas, é possível observar que houve o desenvolvimento de ações estratégicas, que possibilitariam a elaboração do plano: realização de um diagnóstico municipal, a eleição de prioridades, formação de propostas de ações sobre a realidade municipal, proposição de metas e a discussão com a comunidade a fim de superar os desafios e construir o plano que corresponda às necessidades da população (SECCHI, 2014; ARAÚJO; TAPIA, 1991).

Porém, esses dados não se encontram sistematizados, como parte de um plano de ação, nem tampouco disponíveis para que possam ser verificados e acompanhados pela população, conforme preconiza o documento norteador de elaboração dos planos de educação (BRASIL, 2005).

Apesar da demonstração de um compromisso dos municípios que compõem a região do Alto Tietê com a elaboração do planejamento de longo prazo da política 
educacional municipal (BRASIL, 2014), percebe-se que os municípios, em sua maioria, isto é, 77\%, não utilizaram a página do município na internet para a divulgação das discussões acerca da elaboração do Plano Municipal. Apenas 33\% dos municípios disponibilizaram o texto do Plano Municipal de Educação em suas páginas, porém, não de maneira acessível à consulta fácil e rápida, sendo necessário acessar a página em que constam todas as leis municipais (ROTHBERG, 2010).

Há uma ideia muito restrita sobre transparência de dados para a administração pública dos municípios analisados. Percebe-se que há o entendimento de que apenas a abertura das contas públicas, previsões orçamentárias e contratos com a administração já caracterizam um governo que oportuniza publicidade de seus atos à população (BERBERIAN; MELLO; CAMARGO, 2014).

A abertura dos dados sobre o planejamento das políticas públicas, assim como a disponibilização de programas de governo em sintonia com as propostas defendidas durante a corrida eleitoral, traduziriam um compromisso do governante com a população (SALISBURY, 1995; SOUZA, 2006). Apenas Guarulhos publicou o plano de governo no site do município, porém, em contraponto, foi a única cidade que não apresentou o seu plano de educação até dezembro de 2015.

É relevante o fato apontado por Leal (2014, p. 60) sobre o despreparo historicamente observado no corpo burocrático municipal, o que pode inviabilizar a elaboração de documentos que auxiliem o governante em sua gestão e que deem uma resposta aos anseios da população quanto à apresentação de soluções aos problemas municipais, refletindo na dificuldade municipal em planejar ou, ao menos, de dar publicidade às suas ações e políticas públicas (POSSAMAI, 2011).

\section{CONSIDERAÇÕES FINAIS}

Os governos realizam suas atividades a fim de proporcionar a superação de problemas públicos. Assim, o estudo das políticas públicas é importante para contribuir para o desenvolvimento econômico da sociedade e para a redução das desigualdades sociais.

A estruturação das políticas em sistemas únicos auxilia a sua gestão, que se dá por meio da coordenação das ações intergovernamentais pela União. Dessa forma, o governo federal oferece diretrizes gerais e define as formas de financiamento de suas 
ações, como se verifica no Sistema Único de Saúde (SUS). Essa perspectiva isomórfica pode ser associada à teoria institucional, que explica a homogeneização das instituições como forma de superar as incertezas ambientais.

As sociedades atuais, dinâmicas, apresentam certa instabilidade. Nessa perspectiva, as políticas públicas são compreendidas como respostas dadas pelo sistema político às demandas ambientais, por meio de um processo complexo, compreendido em diversas etapas.

O financiamento da política pública é algo que garante a sua continuidade. A elaboração das Leis Orçamentárias a partir da programação efetuada no Plano Plurianual permite que os governantes realizem um planejamento de médio prazo, com responsabilidade fiscal.

Compreende-se que a população tem o direito de acompanhar a aprovação dessas peças orçamentárias e de fiscalizar a sua execução. Porém, a simples divulgação, sem sua devida interpretação, fere o princípio da clareza ou inteligibilidade, uma vez que não permite a apropriação real de seu conteúdo, devido à tecnicidade do documento.

Nessa perspectiva, a Parceria Governo Aberto vislumbra uma maior participação da população, de maneira efetiva, nesse planejamento. O Brasil, como um dos signatários, comprometeu-se a compartilhar informações sobre as ações governamentais e a ampliar o acesso a novas tecnologias que propiciem a abertura e prestação de contas.

Porém, no estudo realizado, verificou-se que os municípios ainda encontram dificuldades em disponibilizar os dados que tratam sobre o planejamento das políticas públicas de educação.

A maioria dos municípios não divulgou em suas páginas na internet a realização de audiências públicas, de forma a fomentar a participação popular nas discussões sobre os Planos Municipais de Educação em 2015. Observou-se que não há uma preocupação dos governantes em dar publicidade aos seus planos de governos, inclusive de suas ações na área de educação, o que dificulta a fiscalização da população do cumprimento das promessas de governo. Os planos de educação, recentemente elaborados, não encontram espaço nas páginas das respectivas prefeituras, o que denota uma ausência de preocupação em divulgar essas informações à população.

Observa-se, assim, que a elaboração dos planos de educação obedeceu apenas a uma imposição legal, representando um documento formal, sem garantia de efetivação 
dos direitos de participação popular na elaboração das políticas públicas e na fiscalização da sua execução. Dessa forma, conclui-se que há um caminho a ser percorrido para que haja uma compreensão da importância estratégica dos Planos Municipais de Educação para o desenvolvimento da política de educação nos municípios estudados, assim como, da participação popular para a sua efetividade.

\section{REFERÊNCIAS}

ABRUCIO, Fernando Luiz. Federalismo e Educação no Brasil: trajetória recente e principais desafios. Associação Brasileira de Magistrados, Promotores de Justiça e Defensores Públicos da Infância e da Juventude - ABMP; Todos Pela Educação (Org.). Justiça pela Qualidade na Educação, São Paulo: Saraiva, 2013, p. 205-220.

ALMEIDA, Guilherme Henrique de La Rocque. O Estado Brasileiro Contemporâneo. In: OLIVEIRA PEREIRA. Cláudia Fernanda (Org.). O Novo Direito Administrativo Brasileiro: o Estado, as agências e o terceiro setor, Belo Horizonte: Fórum, 2003, p. 113-149.

ALMEIDA, M. H. T. O Estado no Brasil contemporâneo: um passeio pela história. MELO, C. R.; SÁEZ, M. A. (Org.). A democracia brasileira: balanço e perspectivas para o Século 21, Belo Horizonte: UFMG, 2007.

ARAÚJO, Angela M. C. e TAPIA, Jorge R. B. Corporativismo e Neocorporativismo: o Exame de duas Trajetórias. Revista Brasileira de Informação Bibliográfica em Ciências Sociais - BIB, n. 32, 1991, p. 1-39.

ARRETCHE Marta Teresa da Silva. Estado federativo e políticas sociais: determinantes da descentralização, São Paulo: FAPESP, 2000.

BERBERIAN, Cynthia de Freitas Q.; MELLO, Patricia Jussara Sari Mendes de; CAMARGO, Renata Miranda Passos. Governo Aberto: a tecnologia contribuindo para maior aproximação entre o Estado e a Sociedade. Revista TCU, Brasília, v. 131, p. 30- 39, set./dez., 2014. Disponível em: <http://revista.tcu.gov.br/ojsp/index.php/RTCU/article/view/60>. Acesso em 15 dez., 2015.

BORGES, Felipe Amaral; TOMETICH, Patrícia. Diversidade com isomorfismo: refletindo sobre a institucionalização do sistema nacional de cultura. II Congresso Brasileiro de Estudos Organizacionais, Uberlândia, 19 a 21 de novembro de 2014. Disponível em:

<http://www.agenciaapollo.com.br/cbeo_avaliacao/anais/1817GT8.pdf>. Acesso em: 30 jan., 2016.

BRANCO, Marcello Simão. O federalismo em conceitos e na realidade brasileira. In: Humberto Dantas; José Paulo Martins Júnior (Org.). Introdução à Política 
Brasileira, 1. ed., São Paulo: Paulus, 2007, p. 109-124.

BRASIL. Constituição da República Federativa do Brasil de 1988. Disponível em: <http://www.planalto.gov.br/ccivil_03/Constituicao/Constituicao.htm>. Acesso em 22 out., 2015.

Ministério da Educação. Manual de Orientação do FUNDEF, 4. ed., 2003. Disponível em: <http://portal.mec.gov.br/arquivos/pdf/manual.pdf>. Acesso em 20 jun., 2016.

. Ministério da Educação. Documento Norteador para Elaboração de Plano Municipal de Educação, 2005. Disponível em:

<http://portal.mec.gov.br/seb/arquivos/pdf/2006/elabpne.pdf>. Acesso em 17 out., 2015.

Lei 13.005, de 25 de junho de 2014, Aprova o Plano Nacional de Educação - PNE e dá outras providências. Disponível em: <http://www.planalto.gov.br/ccivil_03/_ato2011-2014/2014/lei/113005.htm>. Acesso em 23 mai., 2016.

Ministério da Educação. Planejando a próxima década: Alinhando os Planos de Educação, 2014. Disponível em:

$\leq$ http://pne.mec.gov.br/images/pdf/pne_alinhando_planos_educacao.pdf $>$. Acesso em 25 ago., 2015.

. Ministério da Educação. PNE em Movimento, 2015. Disponível em: <http://pne.mec.gov.br/>. Acesso em 15 dez., 2015.

Histórico do Governo Eletrônico, 2016, Brasília, DF, disponível em: <https://www.governoeletronico.gov.br/o-gov.br/historico>. Acesso em: 1º. mai., 2016.

CAMPOS, Rosana; PAIVA, Denise; GOMES, Suely. Gestão da informação pública: um estudo sobre o Portal Transparência Goiás. Sociedade e estado, Brasília, v. 28, n. 2, p. 393-417, ago., 2013. Disponível em: <http://www.scielo.br/scielo.php?script=sci_arttext\&pid=S010269922013000200012\&lng=en\&nrm=iso>. Acesso em 23 mai., 2016.

COBB T. W.; ELDER, C. D. Participation in American politics: the dynamics of agenda building. Baltimore: Johns Hopkins University Press, 1983.

CORAIOLA, Diego Maganhotto et al. Conciliando agência e contexto na dinâmica da mudança institucional. Caderno EBAPE.BR, Rio de Janeiro, v. 13, n. 4, p. 701726, dez., 2015. Disponível em:

<http://www.scielo.br/scielo.php?script=sci_arttext\&pid=S1679-

39512015000400004\&lng=en\&nrm=iso>. Acesso em 1º. mai., 2016.

DAGNINO, Renato; COSTA, Greiner. Do Estado Herdado ao Estado Necessário: uma visão sobre o desafio central da gestão pública. DAGNINO, Renato; COSTA, Greiner (Org.). Gestão Estratégica em Políticas Públicas, São Paulo: Alínea, 2013. 
DAVIES, Nicholas. “Fundeb: A Redenção da Educação Básica?” Revista Educação e Sociedade, Campinas, vol. 27, n. 96 - especial, p. 753-774, out., 2006. Disponível em: <http://www.scielo.br/pdf/es/v27n96/a07v2796.pdf>. Acesso em: $1^{\circ}$. jun., 2016.

DEUBEL, André-Noël Roth. Políticas públicas: formulación, implementación y evaluación, Bogotá: Aurora, 2002. Disponível em:

<https://adep2011.files.wordpress.com/2011/09/roth_andre-politicas-publicas1.pdf>. Acesso em 1º. mai., 2016.

DIMAGGIO, Paul J.; POWELL, Walter W. Jaula de ferro revisitada: isomorfismo institucional e racionalidade coletiva nos campos organizacionais. In: Caldas, M. P.; Bertero, C. O. (coord.) Teoria das Organizações, São Paulo: Atlas, 2006.

DIMAGGIO, Paul J.; POWELL, Walter W. The iron cage revisited institutional isomorphism and collective rationality in organizational fields. American Sociological Review, v. 48, p. 147-160, apr., 1983.

DYE, T. R. The policy analysis, Alabama: The University of Alabama Press, 1976.

EASTON, David. Uma teoria de análise política, Rio de Janeiro: Zahar, 1968.

EASTON, David. Categorias para a Análise de Sistemas em Política. In: EASTON, David (Org.). Modalidades de análise política, Rio de Janeiro: Zahar, 1970.

FARAH, M. F. Parcerias, novos arranjos institucionais e políticas públicas no nível local de governo. RAP - Revista de Administração Pública, Rio de Janeiro, v. 35, p. 119-144, jan./fev., 2001. Disponível em:

<http://bibliotecadigital.fgv.br/ojs/index.php/rap/article/viewFile/6364/4949>. Acesso em: 15 fev., 2016.

FERNANDES, Antônio Sérgio Araújo. "Políticas Públicas: Definição, Evolução e o Caso Brasileiro na Política Social." Introdução à Política Brasileira. DANTAS, Humberto e MARTINS JÚNIOR, José Paulo, São Paulo: Editora Paulus, 2007.

FERREIRA, Luiz Antônio Miguel. NOGUEIRA, Flávia Maria de Barros. Impactos das políticas educacionais no cotidiano das escolas públicas, 2015. Disponível em: <http://pne.mec.gov.br/images/pdf/Noticias/impactos_politicas_educacionais_cotidiano _escolas_publica_PNE.pdf>. Acesso em: 25 dez., 2015.

FINKLER, Lirene; DELL'AGLIO, Débora Dalbosco. Reflexões sobre avaliação de programas e projetos sociais. Barbaroi, Santa Cruz do Sul, n. 38, p. 126-144, jun., 2013. Disponível em $<$ http://pepsic.bvsalud.org/scielo.php?script=sci_arttext\&pid=S010465782013000100008\&lng=pt\&nrm=iso>. Acesso em 4 mai., 2016.

GARCIA, Maria. Federalismo e autonomia dos entes federados em relação ao direito à Educação. Associação Brasileira de Magistrados, Promotores de Justiça e Defensores Públicos da Infância e da Juventude - ABMP; Todos Pela Educação 
(Org.). Justiça pela Qualidade na Educação. Saraiva: 2013, p. 175-204.

GOMES, Emerson Cesar da Silva. O financiamento da Educação Básica no Brasil. Associação Brasileira de Magistrados, Promotores de Justiça e Defensores Públicos da Infância e da Juventude - ABMP; Todos Pela Educação (Org.). Justiça pela Qualidade na Educação. Saraiva: 2013, p. 266-287.

HOWLETT, Michael; RAMESH, M.; PERL, Anthony. Política Pública: seus ciclos e subsistemas: uma abordagem integral, Rio de Janeiro: Elsevier, 2013.

LEAL, Victor Nunes. Coronelismo, enxada e voto, 7. ed., São Paulo: Companhia das Letras, 2012.

LIMA, Luciana Leite; D’ASCENZI, Luciano. Implementação de políticas públicas: perspectivas analíticas. Revista Sociologia e Política, Curitiba, v. 21, n. 48, p. 101110, dez., 2013. Disponível em:

<http://www.scielo.br/scielo.php?script=sci_arttext\&pid=S0104-

44782013000400006\&lng=en\&nrm=iso>. Acesso em 23 jun., 2016.

MAGANO, Octávio Bueno. Liberalismo, corporativismo, pluralismo e neocorporativismo. Revista da Faculdade de Direito da Universidade de São Paulo, v. 78, 1983, p. 52-64. Disponível em: 〈http://dx.doi.org/10.11606/issn.23188235.v78i0p52-64>. Acesso em 1º. mai., 2016.

MARQUES, Eduardo. As políticas públicas na ciência política. MARQUES, Eduardo, FARIA, Carlos Aurélio Pimenta de (Org.). A política pública como campo multidisciplinar, São Paulo: UNESP, Rio de Janeiro: FIOCRUZ, 2013.

MATIAS-PEREIRA, José. Curso de Planejamento Governamental: foco nas políticas públicas e nos indicadores sociais, São Paulo: Atlas, 2012.

MELO, Marcus André. O Sucesso Inesperado das Reformas de Segunda Geração: Federalismo, Reformas Constitucionais e Política Social. Dados, Rio de Janeiro, v. 48, n. 4, 2005, p. 845-889.

MENDES, Eugênio Vilaça. 25 anos do Sistema Único de Saúde: resultados e desafios. Estudos Avançados, 2013, v. 27, n. 48, p. 27-34.

MORGAN, Gareth. Imagens da Organização, São Paulo: Atlas, 1996.

PARCERIA PARA GOVERNO ABERTO. Declaração de Governo Aberto, 2011. Disponível em: <http://www.governoaberto.cgu.gov.br/central-deconteudo/documentos/arquivos/declaracao-governo-aberto.pdf $>$. Acesso em 4 mai., 2016.

POSSAMAI, Ana Júlia. Democratização do Estado na era digital: e-Participação no ciclo de políticas públicas, 2011, 75s. Dissertação (Mestrado em Ciência Política). Universidade Federal do Rio Grande do Sul, Porto Alegre, 2011. Disponível em: $\langle$ http://www.lume.ufrgs.br/bitstream/handle/10183/37815/000821702.pdf?sequence=1 > Acesso em $1^{\circ}$. mai., 2016.

Revista Eletrônica Gestão e Serviços v.7, n. 2, pp. 1727-1750, Julho/Dezembro 2016. ISSN Online: 2177-7284 e-mail: $\underline{\text { regs @ metodista.br }}$ 
PRADO, Sergio. “A 'Federação Inconclusa': O Papel dos Governos Estaduais na Federação Brasileira." O Federalismo Brasileiro em seu Labirinto: Crise e Necessidade de Reformas, REZENDE, Fernando (Org.), Rio de Janeiro: FGV Editora, 2013.

PREFEITURA DA ESTÂNCIA HIDROMINERAL DE POÁ. Portal de

Transparência. Disponível em: $<$ http://www.prefeituradepoa.sp.gov.br/novo/>. Acesso em 15 dez., 2015.

PREFEITURA DE ARUJÁ. Governo Transparente. Disponível em <http://www.prefeituradearuja.sp.gov.br/transparent.php>. Acesso em 15 dez., 2015.

PREFEITURA DE BIRITIBA MIRIM. Portal da Transparência. Disponível em: $<$ http://177.139.137.221/pmbiritibamirim/websis/portal_transparencia/financeiro/contas _publicas/index.php>. Acesso em 15 dez., 2015.

PREFEITURA DE FERRAZ DE VASCONCELOS. Portal da Transparência. Disponível em: <www.ferrazdevasconcelos.sp.gov.br>. Acesso em 15 dez., 2015.

PREFEITURA DE GUARAREMA Portal da Transparência. Disponível em: $<$ http://www.guararema.sp.gov.br/985/portal+da+transparencia/portal+da+transparencia + app/>. Acesso em 15 dez., 2015.

PREFEITURA DE GUARULHOS. Educação. Disponível em: $<$ http://www.guarulhos.sp.gov.br/index.php?option=com_content\&view=article\&id=12 $2 \&$ Itemid=195>. Acesso em 15 dez., 2015.

PREFEITURA DE ITAQUAQUECETUBA. Legislação Municipal de Itaquaquecetuba. Disponível em: $<$ https://leismunicipais.com.br/prefeitura/sp/itaquaquecetuba>. Acesso em 15 dez., 2015.

PREFEITURA DE MOGI DAS CRUZES. Portal da Transparência. Disponível em: <http://www.transparencia.pmmc.com.br/>. Acesso em 15 dez., 2015.

PREFEITURA DE SANTA ISABEL. Portal da transparência. Disponível em: $<$ http://www.transparencia.santaisabel.sp.gov.br/Portal/transparenciadosmunicipios.asp x>. Acesso em 15 dez., 2016.

PREFEITURA DE SUZANO. Transparência. Disponível em: <http://suzano.sp.gov.br/web/transparencia/>. Acesso em 15 dez., 2015.

PREFEITURA MUNICIPAL DA ESTÂNCIA TURÍSTICA DE SALESÓPOLIS. Portal da Transparência. Disponível em: <http://transparencia.salesopolis.sp.gov.br/SLS/>. Acesso em 15 dez., 2015.

PROCOPIUCK, Mario. Políticas Públicas e Fundamentos da Administração Pública: análise e avaliação, governança e redes de políticas, administração 
judiciária, São Paulo: Atlas, 2013.

ROSSETTO, Adriana Marques; ROSSETTO, Carlos Ricardo. Teoria institucional e dependência de recursos na adaptação organizacional: uma visão complementar. Revista de Administração Pública, 2005, v. 4, n. 1 Art. 7, jan./jul., 2005.

ROTHBERG, Danilo. Contribuições a uma teoria da democracia digital como suporte à formulação de políticas públicas. Revista Ibero-americana de Ciencia, Tecnología Y Sociedad. Ciudad Autónoma de Buenos Aires, v. 5, n. 14, p. 6987, abr., 2010. Disponível em: <http://www.ipea.gov.br/participacao/images/pdfs/democraciadigital/rothberg2010.pdf> Acesso em 1º. mai., 2016.

SALISBURY, Robert $H$. The analysis of public policy: a search for theories and roles. THEODOULOU, Stella Z; CAHN, Matthew A. Public Policy: the essential readings. Upper Saddle River, New Jersey: Prentice-Hall, 1995.

SARAIVA, Enrique. Introdução à teoria da política pública. SARAIVA, Enrique;

FERRAREZI, Elisabete (Org.). Coletânea de políticas públicas: volume 1: introdução à teoria da política pública, Brasília: ENAP, 2006. Disponível em: $<$ http://repositorio.enap.gov.br/bitstream/handle/1/1254/cppv1_0101_saravia.pdf?seque nce $=1 \&$ isAllowed=y $>$. Acesso em $1^{\circ}$. mai., 2016.

SAVIANI, Dermeval. Sistema Nacional de Educação articulado ao Plano Nacional de Educação. Revista Brasileira de Educação, Rio de Janeiro, v. 15, n. 44, p. 380412. mai./ago., 2010. Disponível em:

<http://www.scielo.br/pdf/rbedu/v15n44/v15n44a13.pdf>. Acesso em 15 fev., 2016.

SECCHI, L. Políticas Públicas: conceitos, esquemas de análise, casos práticos, São Paulo: Cengage Learning, 2014.

SEGATTO, CATARINA IANNI; ABRUCIO, FERNANDO LUIZ. A cooperação em uma federação heterogênea: o regime de colaboração na educação em seis estados brasileiros. Revista Brasileira de Educação, Rio de Janeiro, v. 21, n. 65, p. 411-429, jun., 2016. Disponível em:

<http://www.scielo.br/scielo.php?script=sci_arttext\&pid=S 1413-

24782016000200411\&lng=en\&nrm=iso>. Acesso em 2 mai., 2016.

SILVA, Rogério Luiz Nery da. Políticas públicas e administração democrática. Sequência (Florianópolis), Florianópolis, n. 64, p. 57-85, jul., 2012. Disponível em: $<$ http://www.scielo.br/scielo.php?script=sci_arttext\&pid=S2177-

70552012000100004\&lng=en\&nrm=iso >. Acesso em: 4 mai., 2016.

SOUZA, Celina. Políticas Públicas: questões temáticas e de pesquisa. Dossiê: Políticas Públicas - Caderno CRH, Brasília, DF, v. 16, n. 39, 2003, p. 11-24. Disponível em: 〈http://www.cadernocrh.ufba.br/viewissue.php?id=12〉. Acesso em 29 dez., 2015.

Celina. Políticas Públicas: uma revisão da literatura. Sociologias, Porto 
Alegre, ano 8, n. 16, jul./dez., 2006, p. 20-45.

TREVISAN, Andrei Pittol; BELLEN, Hans Michael Van. Avaliação de políticas públicas: uma revisão teórica de um campo em construção. Revista de

Administração Pública, Rio de Janeiro: FGV, v. 42, mai./jun., 2008. Disponível em: <http://www.scielo.br/pdf/rap/v42n3/a05v42n3.pdf 